\title{
Interval Forecasting in Supply Chain with Small Sample
}

\author{
Lifeng $W u$ a $(\mathbb{D}$ and Yan Chen \\ College of Management Engineering and Business, Hebei University of Engineering, Handan 056038, China \\ Correspondence should be addressed to Lifeng Wu; wlf6666@126.com
}

Received 31 July 2018; Accepted 18 September 2018; Published 1 October 2018

Academic Editor: Rafał Stanisławski

Copyright (C) 2018 Lifeng Wu and Yan Chen. This is an open access article distributed under the Creative Commons Attribution License, which permits unrestricted use, distribution, and reproduction in any medium, provided the original work is properly cited.

\begin{abstract}
To deal with the forecasting with small samples in the supply chain, three grey models with fractional order accumulation are presented. Human judgment of future trends is incorporated into the order number of accumulation. The output of the proposed model will provide decision-makers in the supply chain with more forecasting information for short time periods. The results of practical real examples demonstrate that the model provides remarkable prediction performances compared with the traditional forecasting model.
\end{abstract}

\section{Introduction}

The supply chain forecasting can be made more accurate when human judgements are incorporated into the forecast system [1]. The performance of purely quantitative forecasting method can be flawed when historical data is limited [2]. In certain cases, the number of available samples is so scarce that providing reliable estimates is a challenging problem [3]. In order to analyze and predict the small samples systems accurately, a large number of studies on supply chain forecasting using grey models and improved grey models have been reported [4-7]. The GM(1,1) (grey first-order differential equation model) forecasting model is formulated for solving limited time series data [8]. There is no strict hypothesis for the distribution of parent data. However, the reliability and validity of the $\operatorname{GM}(1,1)$ have never been discussed. First, without considering other causes when using limited time series data, the forecasting of the $\mathrm{GM}(1,1)$ is unreliable and provides insufficient information to a decision-maker. Second, human judgment cannot be incorporated into the forecasting systems. A grey prediction model with fractional-order accumulation is newly proposed and has better performance and more freedom compared with the traditional grey model [9]. Multivariable nonequidistance grey model with fractional order accumulation is discussed [10]. The grey model predictor design is modified by using optimal fractional-order accumulation calculus [11]. The air quality indicators in the Beijing-Tianjin-Hebei region are predicted by the grey prediction model with fractionalorder accumulation [12]. Therefore, in This paper, three grey models with fractional-order accumulation are put forward. The output of the proposed model can obtain a general interval. This interval is not the grey number [13]. It will provide more forecasting information for a short time period. Most importantly, human judgment for future trend is incorporated into the order number of accumulation.

The rest of the paper proceeds as follows. Grey single variable forecasting models with fractional order accumulation are presented in Section 2. The multivariable grey model with fractional order accumulation is proposed in Section 3. Interval forecasting method of grey models for supply chain management is discussed in Section 4. Some conclusions are given in the last section.

\section{Grey Single Variable Forecasting Models with Fractional Order Accumulation}

For the original data sequence $X^{(0)}=\left\{x^{(0)}(1), x^{(0)}(2), \ldots\right.$, $\left.x^{(0)}(n)\right\}$, a new sequence $X^{(p / q)}=\left\{x^{(p / q)}(1), x^{(p / q)}(2), \ldots\right.$, $\left.x^{(p / q)}(n)\right\}$ can be generated by the fractional order accumulated generating operator (FAGO) as $x^{(p / q)}(k)=$ $\sum_{j=1}^{k}\left(\begin{array}{c}k-j+r-1 \\ k-j\end{array}\right) x^{(0)}(j), k=1,2, \ldots, r$ [14]. $\mathrm{GM}^{p / q}(1,1)$ 
TABLE 1: The predictive values of different models.

\begin{tabular}{lccc}
\hline Time & resilience performance & $\mathrm{GM}(1,1)$ & $\mathrm{GM}^{0.7}(1,1)$ \\
\hline 1 & 1763 & 1763 & 1763 \\
2 & 2376 & 2441 & 2384 \\
3 & 2763 & 2685 & 2740 \\
4 & 2983 & 2954 & 3002 \\
5 & 3216 & 3250 & 3211 \\
MAPE & & 2.0 & 0.4 \\
\hline
\end{tabular}

model and grey exponential smoothing are given in the following way.

\section{1. $G M^{p / q}(1,1)$ Model}

Definition 1.

$$
x^{(p / q)}(k)-x^{(p / q)}(k-1)+a z^{(p / q)}(k)=b
$$

is referred to as the original form of the $\mathrm{GM}^{p / q}(1,1)$ model, where $z^{(p / q)}(k)=\left(x^{(p / q)}(k)+x^{(p / q)}(k-1)\right) / 2, k=2,3, \ldots, n$. It is the traditional $\operatorname{GM}(1,1)$ model when $p / q=1$. The ordinary least squares estimate sequence of the $\mathrm{GM}^{p / q}(1,1)$ model satisfies

$$
\left[\begin{array}{l}
\widehat{a} \\
\widehat{b}
\end{array}\right]=\left(B^{T} B\right)^{-1} B^{T} Y
$$

where

$$
\begin{aligned}
& Y=\left[\begin{array}{c}
x^{(p / q)}(2)-x^{(p / q)}(1) \\
x^{(p / q)}(3)-x^{(p / q)}(2) \\
\vdots \\
x^{(p / q)}(n)-x^{(p / q)}(n-1)
\end{array}\right], \\
& B=\left[\begin{array}{cc}
-z^{(p / q)}(2) & 1 \\
-z^{(p / q)}(3) & 1 \\
\vdots & \vdots \\
-z^{(p / q)}(n) & 1
\end{array}\right] .
\end{aligned}
$$

The solution of the whitenization equation $d x^{(p / q)}(t) / d t+$ $a x^{(p / q)}(t)=b$ for $\mathrm{GM}^{p / q}(1,1)$ is given by

$$
\widehat{x}^{(p / q)}(t)=\left[x^{(0)}(1)-\frac{\widehat{b}}{\widehat{a}}\right] e^{-\widehat{a} t}+\frac{\widehat{b}}{\widehat{a}},
$$

The $p / q(0<p / q \leq 1)$ order inverse accumulated generating operator (IAGO) of $X^{(p / q)}$ is

$$
\begin{aligned}
\widehat{X}^{(0)} & =\alpha^{(p / q)} \widehat{X}^{(p / q)}=\alpha^{(1)} \widehat{X}^{(1-p / q)}(k) \\
& =\left\{\alpha^{(1)} \widehat{x}^{(1-p / q)}(1), \alpha^{(1)} \widehat{x}^{(1-p / q)}(2), \ldots,\right. \\
& \left.\alpha^{(1)} \widehat{x}^{(1-p / q)}(n)\right\}=\left\{\widehat{x}^{(0)}(1), \hat{x}^{(1-p / q)}(2)-\widehat{x}^{(0)}(1), \ldots,\right. \\
& \left.\widehat{x}^{(1-p / q)}(n)-\widehat{x}^{(1-p / q)}(n-1)\right\} .
\end{aligned}
$$
follows.

The procedures of $\mathrm{GM}^{p / q}(1,1)$ can be summarized as

Step 1. For the sequence $x^{(0)}=\{1763,2376,2763,2983,3216\}$

from [4], 0.7-order accumulation sequence $x^{(0.7)}=$ $\{1763,3610,5475,7275,9094\} . B$ and $Y$ in (2) are

$$
\begin{aligned}
& B=\left[\begin{array}{ll}
-2687 & 1 \\
-4543 & 1 \\
-6375 & 1 \\
-8184 & 1
\end{array}\right], \\
& Y=\left[\begin{array}{l}
1847 \\
1865 \\
1800 \\
1819
\end{array}\right] .
\end{aligned}
$$

Step 2. Substituting $B$ and $Y$ into (2), we have the parameters $a, b$. Then $\mathrm{GM}^{0.7}(1,1)$ can be represented as

$$
\frac{d x^{(0.7)}(t)}{d t}+0.008 x^{(0.7)}(t)=1877, \quad t=1,2, \cdots
$$

Step 3. The 0.7 -order accumulated generating operation values $\widehat{x}^{(0.7)}$ can be obtained by employing (4):

$$
\widehat{x}^{(0.7)}=\{1763,3618,5458,7283,9094\} \text {. }
$$

The 2 -order accumulated generating operation values $\hat{x}^{(1)}$ is

$$
\widehat{x}^{(1)}=\widehat{x}^{(0.7)(0.3)}=\{1763,4147,6888,9890,13101\} .
$$

The predicted values $\widehat{x}_{1}^{(0)}$ are $\widehat{x}_{1}^{(0)}=\{1763,2384,2740$, $3002,3211\}$, which are listed in Table 1 . Mean absolute percentage error $\left(\mathrm{MAPE}=100 \%(1 / n) \sum_{k=1}^{n}\left|\left(x^{(0)}(k)-\hat{x}^{(0)}(k)\right)\right|\right.$ $\left.x^{(0)}(k) \mid\right)$ compares the actual values with the forecasted values to evaluate the precision. The use of intelligent methods is a new trend in the grey models $[15,16]$. In this paper, particle swarm optimization is adopted to find the optimal order which produces the minimum MAPE. The experiments are conducted in the MATLAB R2015b.

The results of Table 1 mean that $\operatorname{GM}^{0.7}(1,1)$ have better performance than the traditional $\operatorname{GM}(1,1)$. To investigate the feasibility of the $\mathrm{GM}^{p / q}(1,1)$ model in the supply chain, the following cases are given. 
TABLE 2: The periodic resilience performance indicators of a firm [4].

\begin{tabular}{llcccc}
\hline Time & RPI 1 & RPI 2 & RPI 3 & RPI 4 & RPI 5 \\
\hline 1 & 2386 & 1345 & 674 & 6784 & 1763 \\
2 & 2399 & 1876 & 567 & 5647 & 2376 \\
3 & 3453 & 2345 & 453 & 4563 & 2763 \\
4 & 3645 & 2784 & 363 & 3743 & 2983 \\
5 & 4064 & 3764 & 278 & 3345 & 3216 \\
\hline
\end{tabular}

TABLE 3: The error analysis of different models.

\begin{tabular}{lccccc}
\hline & RPI 1 & RPI 2 & RPI 3 & RPI 4 & RPI 5 \\
\hline MAPE of GM(1,1) & 6 & 3 & 1 & 3 & 2 \\
MAPE of $\mathrm{GM}^{p / q}(1,1)$ & 4.1 & 2.3 & 0.4 & 1.2 & 0.4 \\
\hline
\end{tabular}

TABLE 4: Actual data of the sales volume of registered printers in Taiwan by year.

\begin{tabular}{|c|c|c|c|c|c|c|c|}
\hline Year & 2002 & 2003 & 2004 & 2005 & 2006 & 2007 & 2008 \\
\hline Sales volume & 1047957 & 1138440 & 1091705 & 1083829 & 981984 & 838822 & 820161 \\
\hline
\end{tabular}

TABLE 5: The forecasting values and MAPE of different models.

\begin{tabular}{lcc}
\hline Forecasting technique & Forecasting value for 2008 & Actual value \\
\hline Moving average & 910403 & MAPE \\
Exponential smoothing & 854168 & 11.0 \\
Quadratic trend & 646699 & 4.1 \\
Cubic trend & 665629 & 21.2 \\
Non-linear trend & 876998 & 18.8 \\
$\mathrm{ANP}$ & 830797 & 6.9 \\
$\mathrm{GM}^{0.4}(1,1)$ & 817142 & 1.3 \\
$\mathrm{GM}(1,1)$ & 836018 & 0.4 \\
\hline
\end{tabular}

TABLE 6: The predictive values of different models (units:ten thousand).

\begin{tabular}{lcccc}
\hline Year & LCD TV demand & single exponential model & AR(2) model & GM $^{0.9}(1,1)$ \\
\hline 2001 & 81 & & 59 & 81 \\
2002 & 150 & 151 & 95 & 197 \\
2003 & 393 & 149 & 53 & 423 \\
2004 & 970 & 567 & 505 & 898 \\
2005 & 2018 & 1086 & 1092 & 1903 \\
2006 & 4300 & 2682 & 2551 & 4026 \\
MAPE & & 37.6 & 41.1 & 10.9 \\
\hline
\end{tabular}

The Supply Chain Performance Resilience Forecasting Example [4]. The periodic resilience performance indicators of case firm are listed in Table 2. By $\operatorname{GM}^{p / q}(1,1)$, respectively, the forecasting values and MAPE of different models are given in Table 3.

In Table 3, the error analysis shows that $\mathrm{GM}^{p / q}(1,1)$ ensure the best fit of the data to achieve strong prediction capability. $\operatorname{GM}^{p / q}(1,1)$ can predict the supply chain resilience of an Indian electronics manufacturer.

The Sales Volume of Printers Forecasting Example [20]. Shih et al used the sales volume of printers from 2002 to 2007 as training data. The volume of 2008 is the testing data. Actual values are listed in Table 4 and the errors of eight models are shown in Table 5. The results show that the forecasting accuracy of the $\operatorname{GM}^{0.4}(1,1)$ is better than traditional $\operatorname{GM}(1,1)$.

The LCD TV Demand Forecasting Example [19]. Tsaur collected the LCD TV demand data from 2001 to 2006 as shown in Table 6. It was obvious that the collected data are limited time series data, and therefore the possible methods such as $\operatorname{GM}(1,1)$ and single exponential smoothing model were used for forecasting. The forecasting results are shown in Table 6. In Table 6, we find that the $\operatorname{GM}^{p / q}(1,1)$ has 


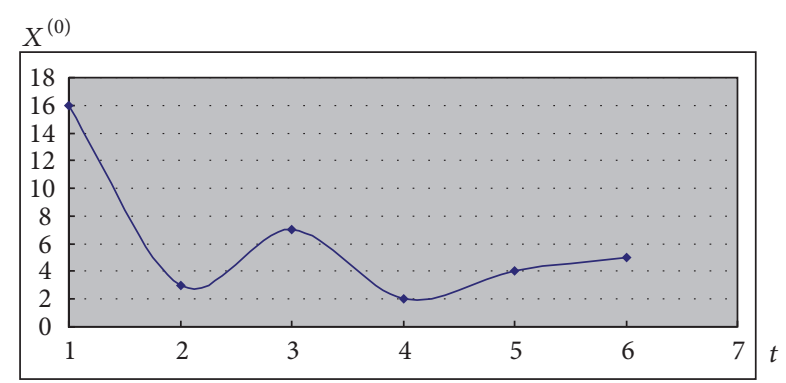

FIgure 1: The line of $X^{(0)}$.

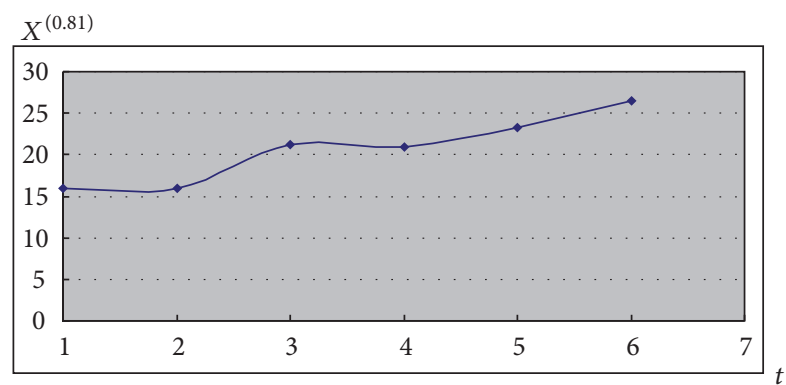

FIgURE 2: The line of $X^{(0.81)}$.

better forecasting performance of MAPE than the single exponential smoothing model.

2.2. Grey Exponential Smoothing Model. FAGO is widely used in grey models for its ability to smooth the randomness of original data [9]. Through FAGO, the disorderly data may be converted into regular form. Actually, by using FAGO, the disorderly sequence may be converted into an approximately increased sequence. For example, $X^{(0)}=\{16,3,7,2,4,5\}$, the 0.81 -AGO sequence is $X^{(0.81)}$ $=\{16,15.96,21.16,20.86,23.28,26.54\}$. The lines of these sequences are illustrated in Figures 1 and 2, respectively. Comparing the two lines, it is clear that the trend of sequence $X^{(0.81)}$ in Figure 2 is more obvious than the sequence $X^{(0)}$ in Figure 1.

An irregular and increased sequence can be predicted by using double exponential smoothing (GDES). Then we give the following definition.

Definition 2 (see [21]). For the original time series $X^{(0)}=$ $\left\{x^{(0)}(1), x^{(0)}(2), \ldots, x^{(0)}(n)\right\}, r$-AGO is given in Definition 1. GDES follows the equations

$$
\begin{aligned}
S^{\prime}(k) & =\alpha x^{(r)}(k)+(1-\alpha) S^{\prime}(k-1) \\
S^{\prime \prime}(k) & =\alpha S^{\prime}(k)+(1-\alpha) S^{\prime \prime}(k-1) \\
b_{k} & =\frac{\alpha}{1-\alpha}\left(S^{\prime}(k)-S^{\prime \prime}(k)\right) \\
a_{k} & =2 S^{\prime}(k)-S^{\prime \prime}(k)
\end{aligned}
$$

where $0 \leq \alpha \leq 1, S^{\prime}(k)$ and $S^{\prime \prime}(k)$ are the single and double exponential smoothing values for time $k$, respectively. The forecasting form is $x^{(r)}(k)=a_{k}+k b_{k}$.

If $r=0$, GDES is the traditional double exponential smoothing. The process of calculating GDES can be summarized as follows.

Step 1. Set the order number $r$ and obtain the $r$-FAGO sequence of $X^{(0)}$ according to Definition 1.

Step 2. Calculate the parameters $\left(a_{k}\right.$ and $\left.b_{k}\right)$ by using Definition 2.

Step 3. Compute the predictive value using $\widehat{x}^{(r)}(k+m)=a_{k}+$ $m b_{k}$, where $m$ is the out-of-sample size.

Step 4. Transform the prediction value back to the original sequence by means of IAGO [21].

In this paper, the predictive values are calculated by using different $\alpha^{\prime}$ s. The $\alpha$ that produces a small mean square error for the fitted values and shows an expected future growth is chosen. We assumed that $S^{\prime}(0)$ and $S^{\prime \prime}(0)$ are equal to the initial historical values.

In this case, the data from [17] is the spare demand of a firm. The accuracy of demand forecast significantly affects the firm's sustainability and profitability. To compare the GDES with traditional double exponential smoothing, the smoothing constant of GDES and traditional double exponential smoothing is set to $\alpha=0.69$. The predictive values of two models are shown in Table 7.

As shown in Table 7, GDES can enhance the accuracy of small data forecasting.

\section{The Multivariable Grey Model with Fractional Order Accumulation}

The existing multivariable grey models $(\mathrm{GMC}(1, \mathrm{~N}))$ all used first-order accumulated generating operation sequence [2226]. In this section, the fractional order accumulated generating operation sequence is introduced into the $\operatorname{GMC}(1, \mathrm{~N})$ model.

Definition 3. It is assumed that $X_{1}^{(0)}=\left\{x_{1}^{(0)}(1), x_{1}^{(0)}(2), \ldots\right.$, $\left.x_{1}^{(0)}(r)\right\}$ is the sequence of system characteristic and $X_{i}^{(0)}=$ $\left\{x_{i}^{(0)}(1), x_{i}^{(0)}(2), \ldots, x_{i}^{(0)}(r)\right\}(i=2,3, \ldots, N)$ are the sequences of relevant factors. Then

$$
\begin{aligned}
& \frac{d x_{1}^{(p / q)}(t)}{d t}+b_{1} x_{1}^{(p / q)}(t) \\
& =b_{2} x_{2}^{(p / q)}(t)+b_{3} x_{3}^{(p / q)}(t)+\cdots+b_{n} x_{n}^{(p / q)}(t)+u
\end{aligned}
$$

is the $\mathrm{GMC}^{p / q}(1, \mathrm{~N})$ model, where $x_{i}^{(p / q)}(k)$ is the $p / q$ order accumulation of $x_{i}^{(0)}(k), x_{i}^{(p / q)}(k)=$ $\sum_{j=1}^{k}\left(\begin{array}{c}k-j+r-1 \\ k-j\end{array}\right) x_{i}^{(0)}(j), k=1,2, \ldots, r$ [14]. It is the traditional GMC $(1, \mathrm{~N})$ model when $p / q=1$. Using ordinary 
TABLE 7: The predictive values of different models.

\begin{tabular}{lccc}
\hline Year & Actual demand [17] & GDES & traditional double exponential smoothing \\
\hline 2006 & 16 & 16 & 16 \\
2007 & 3 & 3 & -2 \\
2008 & 7 & 9 & 4 \\
2009 & 2 & 2 & -1 \\
2010 & 4 & 4 & 3 \\
2011 & 5 & 6 & 5 \\
MAPE & & 8.5 & 62.4 \\
\hline
\end{tabular}

TABLE 8: The customer perception indicators of engine product [18].

\begin{tabular}{lccccc}
\hline Year & sales volume & energy efficiency & product safety & cost performance & service promptness \\
\hline 2005 & 850.15 & 8.2112 & 1 & 1 & 1 \\
2006 & 972.18 & 8.5027 & 1.0326 & 1.0786 & 1.0405 \\
2007 & 1078.47 & 8.2711 & 1.0352 & 1.1029 & 1.007 \\
2008 & 1069.28 & 8.0806 & 1.0521 & 1.0624 & 0.9818 \\
2009 & 1259.26 & 8.1915 & 1.0846 & 1.0277 & 1.0028 \\
2010 & 1454.51 & 9.0849 & 1.0911 & 1.0705 & 1.1229 \\
2011 & 1413.92 & 8.7934 & 1.0404 & 0.9908 & 1.0796 \\
2012 & 1672.11 & 8.9042 & 1.0612 & 0.9769 & 1.0992 \\
2013 & 1948.23 & 9.3961 & 1.1289 & 1.0243 & 1.1704 \\
2014 & 2063.35 & 9.938 & 1.2214 & 0.9711 & 1.3701 \\
\hline
\end{tabular}

least squares, the parameters of $\operatorname{GMC}^{p / q}(1, \mathrm{~N})$ model are estimated:

$$
\left[\widehat{b}_{1}, \widehat{b}_{2}, \ldots, \widehat{b}_{n}, \widehat{u}\right]^{T}=\left(B^{T} B\right)^{-1} B^{T} Y
$$

where

$$
\begin{aligned}
Y & =\left[\begin{array}{c}
x_{1}^{(p / q)}(2)-x_{1}^{(p / q)}(1) \\
x_{1}^{(p / q)}(3)-x_{1}^{(p / q)}(2) \\
\vdots \\
x_{1}^{(p / q)}(n)-x_{1}^{(p / q)}(n-1)
\end{array}\right], \\
B & =\left[\begin{array}{cccccc}
-0.5\left(x_{1}^{(p / q)}(2)+x_{1}^{(p / q)}(1)\right) & x_{2}^{(p / q)}(2) & \cdots & x_{n}^{(p / q)}(2) & 1 \\
-0.5\left(x_{1}^{(p / q)}(3)+x_{1}^{(p / q)}(2)\right) & x_{2}^{(p / q)}(3) & \cdots & x_{n}^{(p / q)}(3) & 1 \\
\vdots & \vdots & \vdots & \vdots & \vdots \\
-0.5\left(x_{1}^{(p / q)}(r-1)+x_{1}^{(p / q)}(r)\right) & x_{2}^{(p / q)}(r) & \cdots & x_{n}^{(p / q)}(r) & 1
\end{array}\right] .
\end{aligned}
$$

Set $\hat{x}_{1}^{(0)}(1)=x_{1}^{(0)}(1)$; when $t \geq 2$, the convolution integral of the right hand of (12) can also be discretised as

$$
\begin{aligned}
x_{1}^{(p / q)}(t)= & x_{1}^{(0)}(1) e^{-b_{1}(t-1)} \\
& +\sum_{\tau=2}^{t}\left\{e^{-b_{1}(t-\tau+0.5)} \frac{f(\tau)+f(\tau-1)}{2}\right\},
\end{aligned}
$$

where $f(t)=b_{2} x_{2}^{(p / q)}(t)+b_{2} x_{2}^{(p / q)}(t)+\cdots+b_{n} x_{n}^{(p / q)}(t)+u$. Then the $p / q(0 \leq p / q \leq 1)$ order inverse accumulated generating operator of the predicted value is the same as (5).

For example, the customer perception indicators of engine product are listed in Table 8 from [18]. To obtain the sales volume forecasting value, the engine sales volume is $X_{1}^{(0)}$. Energy efficiency, product safety, cost performance, and service promptness are $X_{2}^{(0)}, X_{3}^{(0)}, X_{4}^{(0)}$, and $X_{5}^{(0)}$, respectively. This case has limited data. Thus we can build $\mathrm{GMC}^{p / q}(1,5)$. 
TABLE 9: The predictive values of different models.

\begin{tabular}{lccc}
\hline Year & sales volume & Quadratic polynomial model [18] & GMC $^{0.15}(1,5)$ \\
\hline 2005 & 850.15 & 850.15 & 850.15 \\
2006 & 972.18 & 861.7971 & 965.79 \\
2007 & 1078.47 & 929.5540 & 1055.96 \\
2008 & 1069.28 & 1058.6918 & 1144.18 \\
2009 & 1259.26 & 1103.4097 & 1264.41 \\
2010 & 1454.51 & 1285.5118 & 1399.63 \\
2011 & 1413.92 & 1525.6792 & 1555.71 \\
2012 & 1672.11 & 1567.0815 & 1743.53 \\
2013 & 1948.23 & 1786.3352 & 1934.37 \\
2014 & 2063.35 & 2095.0247 & 2100.82 \\
MAPE & & 8.24 & 3.0 \\
\hline
\end{tabular}

$\operatorname{GMC}^{0.15}(1,5)$ has the smaller MAPE than the $\operatorname{GMC}^{p / q}(1,5)$ with the other accumulated order numbers. Thus the results of $\mathrm{GMC}^{0.15}(1,5)$ are given in Table 9.

By comparing the MAPE in Table 9, the example of demand forecasting for engine products demonstrated the applicability and validity of the $\operatorname{GMC}^{p / q}(1,5)$.

Actually, $X_{1}^{(0)}$ is taken as the supply chain demand. $X_{i}^{(0)}=$ $\left\{x_{i}^{(0)}(1), x_{i}^{(0)}(2), \ldots, x_{i}^{(0)}(r)\right\}(i=2,3, \ldots, N)$ are the sequences of relevant factors. $\mathrm{GMC}^{p / q}(1, \mathrm{~N})$ are suitable to predict the supply chain demand, because $\operatorname{GMC}^{p / q}(1, \mathrm{~N})$ can depict the model more precisely with new degrees of freedom and performances.

\section{Interval Forecasting of Grey Models for Supply Chain Management}

Fractional derivatives accumulate the whole history of the system in weighted form and it is referred to as the memory effect. As we know, big samples forecasting models depend on statistical laws. In this section, the small samples forecasting models which depend on the memory effect are a new path. For example, $x^{(1)}(k)$ in grey forecasting models denotes the weight of $x^{(0)}(i)(i=1,2, \ldots, k)$ as 1 . The larger $p / q$ of $x^{(p / q)}(k)$ is, the larger the weight of old data is. The smaller $p / q$ of $x^{(p / q)}(k)$ is, the smaller the weight of old data is. Reducing $p / q$ can reduce the weights of old data, which can put more emphasis on the newer data.

Although the grey models (including $\mathrm{GM}^{p / q}(1,1)$, $\mathrm{GDES}^{p / q}$, and $\mathrm{GMC}^{p / q}(1, \mathrm{~N})$ ) have better forecasting performance, the input data is too limited and the forecasting values are point estimations which supply too limited information for a decision-maker. In this section, in order to obtain a better fitted model with smaller estimated errors and a smaller support forecasting interval, a novel fractional grey modelling mechanism is applied for solving limited time series data using the following steps.

Actually, for many forecasting cases in the supply chain, the accumulated order number often satisfied $0<p / q<1$. If the future trend is similar to the newer data, the setting value of $p / q$ is smaller. If the future trend is similar to the order data, the setting value of $p / q$ is bigger. In the supply chain. for many forecasting cases with limited information, if it is difficult to judge the future trend, the forecasting value must be in a forecasting interval. The upper value and the lower value of forecasting interval can be obtained by different fractional grey models.

For the original data sequence $X^{(0)}=\left\{x^{(0)}(1), x^{(0)}(2)\right.$, $\left.\ldots, x^{(0)}(n)\right\}$, the forecasting values of $\mathrm{GM}^{0.1}(1,1)$ model (or $\operatorname{GDES}^{0.1}$ and $\left.\operatorname{GMC}^{0.1}(1, \mathrm{~N})\right)$ are denoted as

$$
\widehat{X}_{0.1}^{(0)}=\left\{\widehat{x}_{0.1}^{(0)}(1), \widehat{x}_{0.1}^{(0)}(2), \ldots, \widehat{x}_{0.1}^{(0)}(n)\right\},
$$

and the forecasting values of $\mathrm{GM}^{0.9}(1,1)$ model (or GDES ${ }^{0.9}$ and $\left.\operatorname{GMC}^{0.9}(1, \mathrm{~N})\right)$ are denoted as

$$
\widehat{X}_{0.9}^{(0)}=\left\{\widehat{x}_{0.9}^{(0)}(1), \widehat{x}_{0.9}^{(0)}(2), \ldots, \widehat{x}_{0.9}^{(0)}(n)\right\} .
$$

For the same point $k$, the smaller of $\widehat{x}_{0.9}^{(0)}(k)$ and $\widehat{x}_{0.1}^{(0)}(k)$ is set to the lower value of the forecasting interval. The bigger of $\widehat{x}_{0.9}^{(0)}(k)$ and $\widehat{x}_{0.1}^{(0)}(k)$ is set to the upper value of the forecasting interval. Thus we can obtain a grey forecasting interval. For example,

$$
X^{(0)}=\{1763,2376,2763,2983,3216\},
$$

the forecasting values of $\mathrm{GM}^{0.1}(1,1)$ model (or GDES $S^{0.1}$ and $\left.\operatorname{GMC}^{0.1}(1, \mathrm{~N})\right)$ are

$$
\widehat{X}_{0.1}^{(0)}=\{1763,2353,2756,3023,3197,3307\},
$$

and the forecasting values of $\mathrm{GM}^{0.9}(1,1)$ model (or GDES ${ }^{0.9}$ and $\left.\mathrm{GMC}^{0.9}(1, \mathrm{~N})\right)$ are

$$
\widehat{X}_{0.9}^{(0)}=\{1763,2418,2709,2973,3233,3497\} .
$$

Therefore, the grey forecasting interval values are

$$
\begin{gathered}
\{[1763,1763],[2353,2418],[2709,2756], \\
[2973,3023],[3197,3233],[3307,3497]\} .
\end{gathered}
$$

The above method is called the grey interval model (GIM). To investigate the feasibility of GIM in supply chain forecasting, seven cases are listed as follows. 
TABLE 10: The fitting values of different models.

\begin{tabular}{lccc}
\hline Month & sales volume & $\mathrm{GM}^{0.1}(1,1)$ & $\mathrm{GM}^{0.9}(1,1)$ \\
\hline 1 & 103148 & 103148 & 103148 \\
2 & 119066 & 119269 & 124066 \\
3 & 137468 & 139992 & 143842 \\
4 & 155892 & 162736 & 164238 \\
5 & 186370 & 187063 & 186099 \\
6 & 216230 & 212887 & 209924 \\
7 & 249776 & 240225 & 236108 \\
8 & 266829 & 269135 & 265023 \\
9 & 294475 & 299698 & 297046 \\
10 & 334595 & 332004 & 332578 \\
11 & 365988 & 366158 & 372051 \\
MAPE & & 1.4 & 2.4 \\
\hline
\end{tabular}

TABLE 11: The predictive results of different models.

\begin{tabular}{lccr}
\hline model & sales volume & predictive values & interval value \\
\hline simple linear regression (Xue 2015) & 414032 & 436402 & {$[425763,494570]$} \\
GIM & 414032 & & {$[402269,415940]$} \\
\hline
\end{tabular}

TABLE 12: The predictive results of number of end-of-life vehicles.

\begin{tabular}{lcr}
\hline Year & number of end-of-life vehicles & interval value \\
\hline 2008 & 1977 & {$[1977,1977]$} \\
2009 & 2455 & {$[2407,2567]$} \\
2010 & 2818 & {$[2460,2527]$} \\
2011 & 2266 & {$[2422,2432]$} \\
2012 & 2241 & {$[2319,2369]$} \\
2013 & 2265 & {$[2199,2320]$} \\
\hline
\end{tabular}

Case 1. The data are from [27]. The data come from the sales volume of semiconductor components in a firm. To compare the proposed model with the other model, the data before November are the training set. The fitting values of different models are given in Table 10.

The predictive results (December) of different models are given in Table 11.

We can clearly see from the results given in Table 10 that $\mathrm{GM}^{p / q}(1,1)$ can obtain higher fitting accuracy. From the results given in Table 11, we can see that GIM can obtain shorter intervals including the actual value. But the simple linear regression derives a wide forecasting interval which provides too little information for the decision-maker.

Case 2. The data come from [28]. The data refer to the numbers of end-of-life vehicles in the West Anatolia. Forecasting the return flow of an end-of-life product is important for all decision levels of the reverse supply chain. In this paper, the predictive results of GIM are given in Table 12 . The results of interval value can provide guidance to the managers and practitioners of recovery and recycling systems.

Case 3. The data come from [29]. In recent years, China's high production of thin film transistor liquid crystal display (TFT-LCD) panels has led to intense competition in this industry, causing its supply to be greater than the actual demand. Under such circumstances, reducing inventory levels and inventory turnover is a critical issue faced by panel manufacturers. The production quantity is maintained at an appropriate balance point considering the total cost. To achieve this balance in production marketing coordination, an accurate short-term demand forecast is essential. Because the demand for TFT-LCD panels is affected tremendously by the global business cycle, whereas the business cycle has substantially changed in recent years, the use of numerous long-term historical observations does not satisfy the needs of the short-term forecasts. Therefore, this study applied data produced by a leading Taiwanese TFT-LCD panel manufacturer to verify the forecasting performance of GIM [29]. In this paper, the predictive results of GIM are given in Table 13. The actual value is in the forecasting interval. It demonstrates that GIM can provide more information with predictive values.

Case 4. The data come from [30]. They are the return quantity for a third party e-waste firm in Turkey. The predictive results are listed in Table 14.

The predictive results in Table 14 indicate that $\mathrm{GM}^{0.1}(1,1)$ and $\mathrm{GM}^{0.9}(1,1)$ can obtain small fitting errors. By GIM, the obtained forecasting interval indeed includes the actual value. 
TABLE 13: The predictive results of demand of TFT-LCD panels.

\begin{tabular}{lcccc}
\hline Months & Actual value & $\mathrm{GM}^{0.1}(1,1)$ & $\mathrm{GM}^{0.9}(1,1)$ & interval value \\
\hline 4 & 1.718 & 1.718 & 1.718 & {$[1.718,1.718]$} \\
5 & 1.728 & 1.714 & 1.715 & {$[1.714,1.715]$} \\
6 & 1.714 & 1.735 & 1.740 & {$[1.735,1.740]$} \\
7 & 1.753 & 1.746 & 1.741 & {$[1.741,1.746]$} \\
MAPE & & 0.6 & 0.7 & {$[1.729,1.748]$} \\
8 & 1.742 & 1.748 & 1.729 & \\
\hline
\end{tabular}

TABLE 14: The predictive results of return quantity for third party.

\begin{tabular}{lcccc}
\hline Time & Actual value & $\mathrm{GM}^{0.1}(1,1)$ & $\mathrm{GM}^{0.9}(1,1)$ & interval value \\
\hline 1 & 536.4 & 536.4 & 536.4 & {$[536.4,536.4]$} \\
2 & 538.61 & 538.2 & 535.8 & {$[535.8,538.2]$} \\
3 & 569.35 & 569.6 & 554 & {$[554,569.6]$} \\
4 & 613 & 612.8 & 565.3 & {$[565.3,612.8]$} \\
MAPE & & 0.03 & 2.7 & {$[572.6,664.6]$} \\
5 & 633.32 & 664.6 & 572.6 & \\
\hline
\end{tabular}

TABLE 15: The forecasting interval value of the proposed model.

\begin{tabular}{lcc}
\hline Forecasting technique & Actual value & interval value \\
\hline GIM & 820161 & {$[813065,963371]$} \\
\hline
\end{tabular}

TABLE 16: The forecasting interval value of the proposed model.

\begin{tabular}{lcccc}
\hline Year & Actual demand [17] & GDES $^{0.1}$ & GDES $^{0.9}$ & interval value \\
\hline 2006 & 16 & 16 & 16 & 4 \\
2007 & 3 & -1 & 9 & {$[-1,4]$} \\
2008 & 7 & 5 & 2 & {$[5,9]$} \\
2009 & 2 & 0 & 4 & {$[0,2]$} \\
2010 & 4 & 3 & 6 & {$[3,4]$} \\
2011 & 5 & 5 & & {$[5,6]$} \\
\hline
\end{tabular}

Thus, we can conclude that GIM is effective for limited sample forecasting problems.

Case 5. Shih et al. used the sales volume of printers from 2002 to 2007 as the training data. The volume of 2008 is the testing data [20]. Actual values are listed in Table 4 and the results of GIM are shown in Table 15. The results show that the actual value of 2008 is in the forecasting interval. Thus, we can conclude that GIM is effective for the limited sample forecasting problem.

Case 6. Actual values are listed in Table 7 and the results of GIM are shown in Table 16. As shown in Table 16, the results show that the actual demand values are all in the forecasting interval. It also indicates that highly volatile demand can obtain volatile intervals. These results can provide more information for the supply chain manager. Thus, we can conclude that GIM is effective for limited sample forecasting problems.

Case 7 (see [19]). Tsaur collected the LCD TV demand data from 2001 to 2006 as shown in Table 6. The forecasting results are shown in Table 17 . In Table 17, we find that the interval of GIM is shorter than that of the fuzzy autoregressive model.

\section{Conclusion}

In theory, $\mathrm{GM}^{p / q}(1,1), \mathrm{GDES}^{p / q}$, and $\mathrm{GMC}^{p / q}(1, \mathrm{~N})$ models are discussed in this paper, respectively. Their application scopes are listed in Table 18. The results show that these models outperform the traditional grey models in the prediction precision.

Using traditional grey models, the forecasting values of limited data are point estimations which supply too limited information for a decision-maker. It is easy to arouse suspicion for this kind of point estimations. Thus, a novel interval forecasting method is put forward. From the empirical results, we found that the forecasting capability of the GIM is quite encouraging, but those of the time series models are not. In addition, the interval of GIM is smaller than that of the simple linear regression and fuzzy autoregressive model. In the real world, the environment is uncertain and we can only use a limited amount of data to provide future forecasts for a 
TABLE 17: The predictive results of different models (units:ten thousand).

\begin{tabular}{lccc}
\hline Year & LCD TV demand & the proposed model & fuzzy autoregressive model [19] \\
\hline 2001 & 81 & & {$[82,276]$} \\
2002 & 150 & {$[197,210]$} & {$[318,532]$} \\
2003 & 393 & {$[423,476]$} & {$[687,969]$} \\
2004 & 970 & {$[898,1024]$} & {$[1748,2163]$} \\
2005 & 2018 & {$[1903,2156]$} & {$[4041,4779]$} \\
2006 & 4300 & {$[4026,4493]$} & \\
\hline
\end{tabular}

TABLE 18: The application scopes summary.

\begin{tabular}{lc}
\hline Situation & Method \\
\hline $\mathrm{GM}^{p / q}(1,1)$ & exponential trend \\
$\mathrm{GDES}^{p / q}$ & volatile trend \\
$\mathrm{GMC}^{p / q}(1, \mathrm{~N})$ & multi-variable limited data \\
\hline
\end{tabular}

TABLE 19: The proposed model summary.

\begin{tabular}{lc}
\hline Situation Judgement & Method \\
\hline the future trend is similar to the newer data & $p / q$ is smaller \\
the future trend is similar to the order data & $p / q$ is bigger \\
difficult to judge the future trend & interval forecasting \\
\hline
\end{tabular}

short time period. In this situation, GIM is more satisfactory than the time series model.

In practice, GIM is summarized in Table 19. This paper contributes to the literature with an interval model for small samples forecasting in supply chain. It significantly improves small sample forecasting due to the interval result carrying more information. This paper demonstrates that grey modelling can be successfully applied to the forecasting problem in supply chain. Moreover, the proposed forecasting system can be used as a strategic tool for forecasting under uncertain conditions with a small amount of recent data.

For future research, in order to investigate the feasibility of the novel model in supply chain, it may be used for other real world cases for forecasting and the performances of the methods can be compared.

\section{Data Availability}

All the data are from the references in this paper.

\section{Conflicts of Interest}

The authors declare no conflicts of interest.

\section{Acknowledgments}

The relevant researches carried out in this paper are supported by the National Natural Science Foundation of China (No. 71871084, 71401051, and 71801085). We also acknowledge the Project funded by China Postdoctoral Science Foundation (2018M630562).

\section{References}

[1] P. Goodwin, "Integrating management judgment and statistical methods to improve short-term forecasts," Omega, vol. 30, no. 2, pp. 127-135, 2002.

[2] M. Lawrence, P. Goodwin, M. O'Connor, and D. Önkal, "Judgmental forecasting: A review of progress over the last 25 years," International Journal of Forecasting, vol. 22, no. 3, pp. 493-518, 2006.

[3] D. Sovilj, K.-M. Björk, and A. Lendasse, "Comparison of combining methods using Extreme Learning Machines under small sample scenario," Neurocomputing, vol. 174, pp. 4-17, 2016.

[4] R. Rajesh, "Forecasting supply chain resilience performance using grey prediction," Electronic Commerce Research and Applications, vol. 20, pp. 42-58, 2016.

[5] S.-J. Wang, W.-L. Wang, C.-T. Huang, and S.-C. Chen, "Improving inventory effectiveness in RFID-enabled global supply chain with Grey forecasting model," The Journal of Strategic Information Systems, vol. 20, no. 3, pp. 307-322, 2011.

[6] F. Guo, J. Diao, Q. Zhao, D. Wang, and Q. Sun, "A double-level combination approach for demand forecasting of repairable airplane spare parts based on turnover data," Computers \& Industrial Engineering, vol. 110, pp. 92-108, 2017.

[7] A. Samvedi and V. Jain, "A grey approach for forecasting in a supply chain during intermittentdisruptions," Engineering Applications of Artificial Intelligence, vol. 26, no. 3, pp. 1044-1051, 2013.

[8] Z. Wang, Q. Li, and L. Pei, "A seasonal GM(1,1) model for forecasting the electricity consumption of the primary economic sectors," Energy, vol. 154, pp. 522-534, 2018.

[9] J. Wensong, W. Zhongyu, and Z. P. Mourelatos, "Application of nonequidistant fractional-order accumulation model on trajectory prediction of space manipulator," IEEE/ASME Transactions on Mechatronics, vol. 21, no. 3, pp. 1420-1427, 2016. 
[10] Y. Luo and Q. Liu, "Multivariable non-equidistance grey model with fractional order accumulation and its application," The Journal of Grey System, vol. 30, no. 1, pp. 239-248, 2018.

[11] Y. Yang and D. Xue, "Modified grey model predictor design using optimal fractional-order accumulation calculus," IEEE/CAA Journal of Automatica Sinica, vol. 4, no. 4, pp. 724-733, 2017.

[12] L. Wu, N. Li, and Y. Yang, "Prediction of air quality indicators for the Beijing-Tianjin-Hebei region," Journal of Cleaner Production, vol. 196, pp. 682-687, 2018.

[13] N. Xie and N. Chen, "Flexible job shop scheduling problem with interval grey processing time," Applied Soft Computing, vol. 70, pp. 513-524, 2018.

[14] L. Wu, S. Liu, L. Yao, S. Yan, and D. Liu, "Grey system model with the fractional order accumulation," Communications in Nonlinear Science and Numerical Simulation, vol. 18, no. 7, pp. 1775-1785, 2013.

[15] J. Wang, P. Du, H. Lu, W. Yang, and T. Niu, "An improved grey model optimized by multi-objective ant lion optimization algorithm for annual electricity consumption forecasting," Applied Soft Computing, vol. 72, pp. 321-337, 2018.

[16] B. Zeng and C. Li, "Improved multi-variable grey forecasting model with a dynamic background-value coefficient and its application," Computers \& Industrial Engineering, vol. 118, pp. 278-290, 2018.

[17] G. Feng, C Liu, and W Li, "Research on spares consumption quota prediction based on exponential smoothing method," $J i$ Suan Ji \& Xian Dai Hua, vol. 9, pp. 163-165, 2012.

[18] Y. Li, L. Zeng, and J. Cao, "Demand forecasting model based on perception factors of customer satisfaction," Jisuanji Jicheng Zhizao Xitong/Computer Integrated Manufacturing Systems, CIMS, vol. 23, no. 2, pp. 404-413, 2017.

[19] R.-C. Tsaur, "Insight of the fuzzy grey autoregressive model," Soft Computing, vol. 13, no. 10, pp. 919-931, 2009.

[20] H.-S. Shih, E. Stanley Lee, S.-H. Chuang, and C.-C. Chen, "A forecasting decision on the sales volume of printers in Taiwan: An exploitation of the Analytic Network Process," Computers \& Mathematics with Applications, vol. 64, no. 6, pp. 1545-1556, 2012.

[21] W. Lifeng and Y. Yingjie, "Grey double exponential smoothing model and its application on pig price forecasting in China," Applied Soft Computing, vol. 39, pp. 117-123, 2016.

[22] T.-L. Tien, "The indirect measurement of tensile strength by the new model FGMC $(1, \mathrm{n})$, , Measurement, vol. 44, no. 10, pp. 1884-1897, 2011.

[23] Z.-X. Wang and P. Hao, "An improved grey multivariable model for predicting industrial energy consumption in China," Applied Mathematical Modelling, vol. 40, no. 11-12, pp. 5745-5758, 2016.

[24] X. Ma and Z.-B. Liu, "Research on the novel recursive discrete multivariate grey prediction model and its applications," Applied Mathematical Modelling, vol. 40, no. 7-8, pp. 4876-4890, 2016.

[25] L. Wu, X. Gao, Y. Xiao, Y. Yang, and X. Chen, "Using a novel multi-variable grey model to forecast the electricity consumption of Shandong Province in China," Energy, vol. 157, pp. 327-335, 2018.

[26] L. Wu and Z. Zhang, "Grey multivariable convolution model with new information priority accumulation," Applied Mathematical Modelling: Simulation and Computation for Engineering and Environmental Systems, vol. 62, pp. 595-604, 2018.
[27] X. Wenjun, Design and realization of the model of semiconductor components sales and purchases related forecast, University of Electronic Science and Technology of China, 2015.

[28] S. Ene and N. Öztürk, "Grey modelling based forecasting system for return flow of end-of-life vehicles," Technological Forecasting \& Social Change, vol. 115, pp. 155-166, 2017.

[29] C.-J. Chang, J.-Y. Lin, and P. Jin, "A grey modeling procedure based on the data smoothing index for short-term manufacturing demand forecast," Computational and Mathematical Organization Theory, vol. 23, no. 3, pp. 409-422, 2017.

[30] B. Ayvaz, E. Boltürk, and S. Kaçtioglu, "A grey system for the forecasting of return product quantity in recycling network," International Journal of Supply Chain Management, vol. 3, no. 3, pp. 105-112, 2014. 


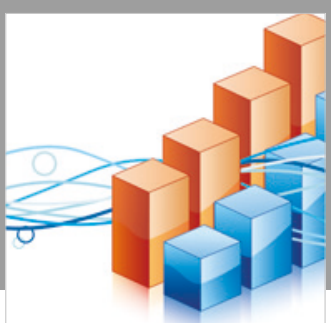

Advances in

Operations Research

\section{-n-m}
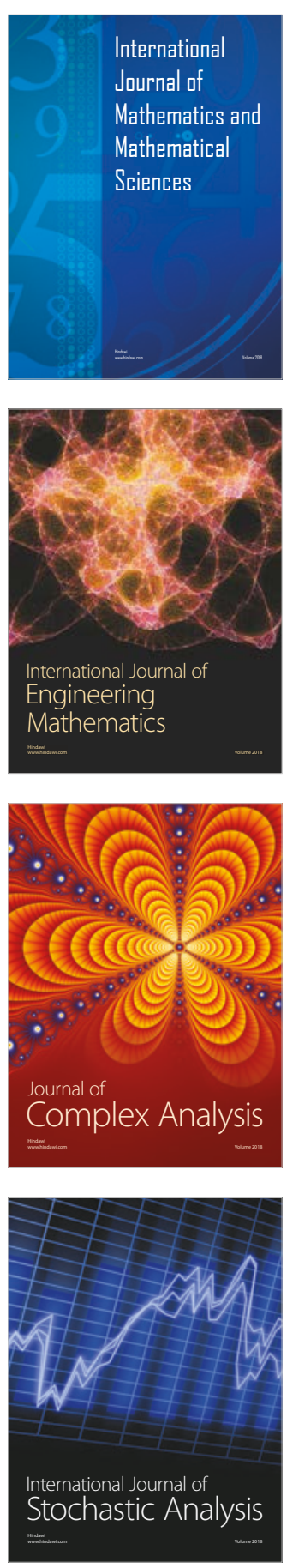
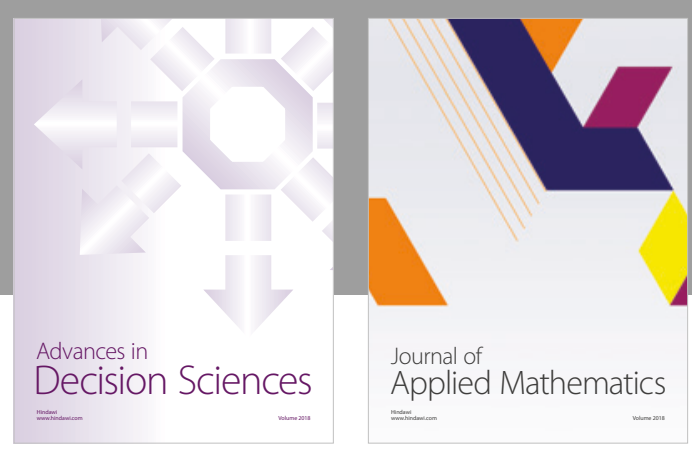

Journal of

Applied Mathematics
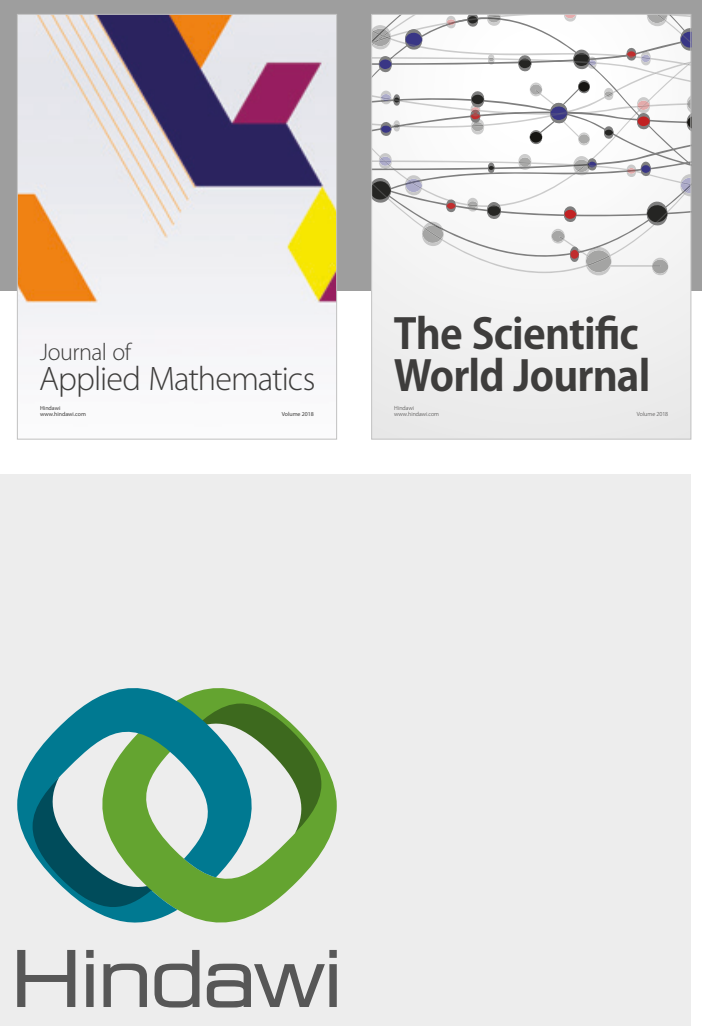

Submit your manuscripts at

www.hindawi.com

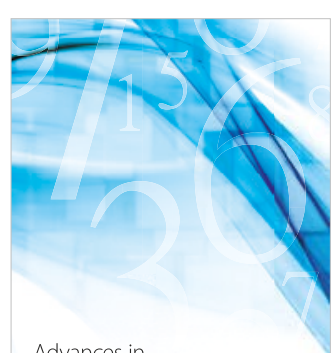

Advances in
Numerical Analysis
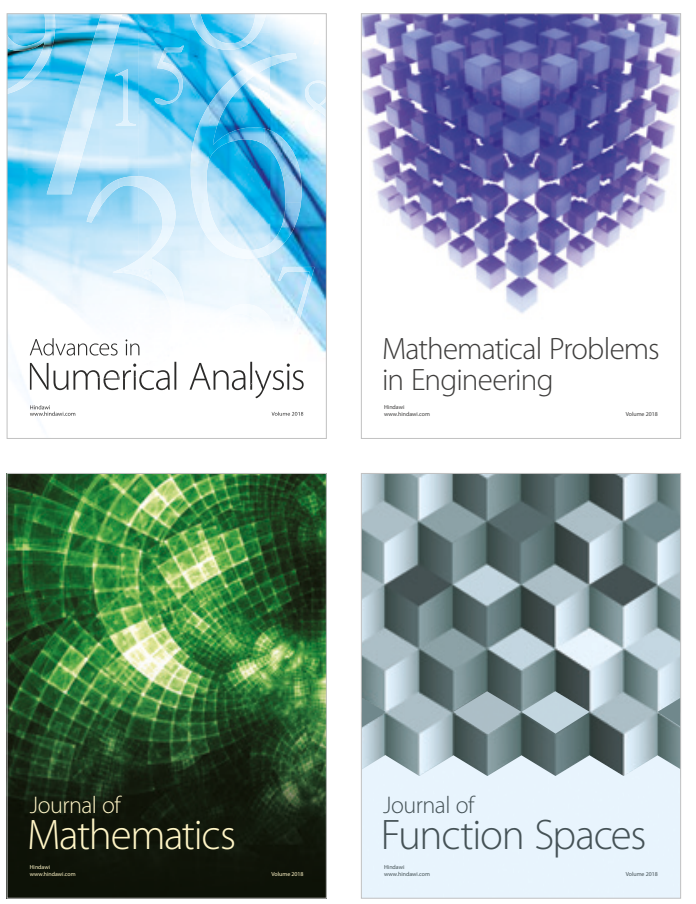

Mathematical Problems in Engineering

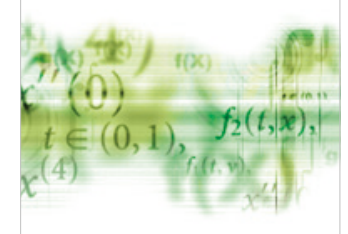

International Journal of

Differential Equations

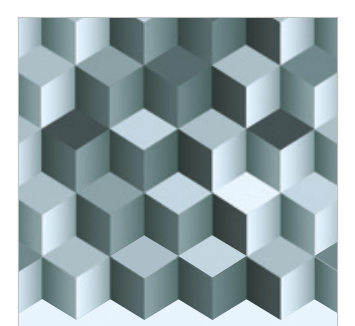

Journal of

Function Spaces

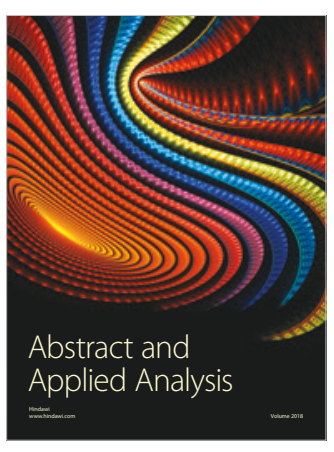

The Scientific

World Journal

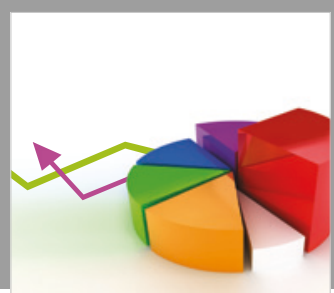

Journal of

Probability and Statistics
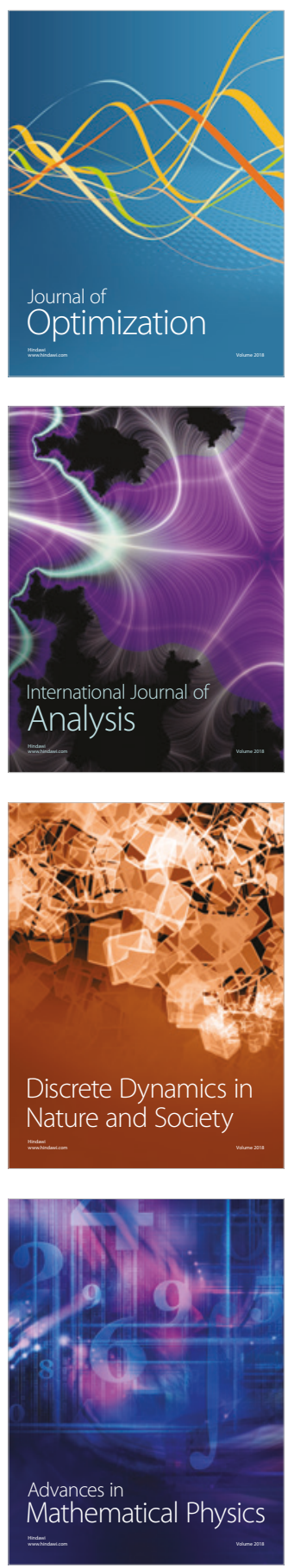